\title{
Buscando uma linguagem para a cibernotícia: (re) conhecendo o leitor/usuário como fator decisivo para definições
}

\begin{abstract}
RESUMO
Este artigo analisa os caminhos de leitura e navegação dos usuários/leitores do jornalismo online, de forma a contribuir para a definição da Internet como mídia. Para isso, leva em conta ainda as características únicas da linguagem nos meios digitais. Verifica, também, a trajetória de desenvolvimento dos meios marcada pela convergência tecnológica, as novas funções do leitor e a formação de uma linguagem específica a partir dessas características, e a possibilidade de fusão conceitual operada pela hipermídia.
\end{abstract}

\section{PALAVRAS-CHAVE}

jornalismo online

convergência

linguagem

\begin{abstract}
This article analyses online journalism, in order to contribute to internet definition of Media, taking into account language unique characteristics as the digital means. It also examines the as well as development of trajectory means marked by technological convergence, readers new functions, the formation of a specific language out of these characteristics as well as the possibility of a conceptual fusion operated by hipermedia.
\end{abstract}

\section{KEY WORDS}

online journalism

convergence

language
Desde a invenção do rádio e depois da televisão, especula-se se um ou outro desapareceria, dando lugar ao mais novo, ao mais moderno. A história tem mostrado que eles não desapareceram, mas contribuíram na trajetória de disseminação mútua e do desenvolvimento de sua linguagem. Este processo se renova na atualidade com a ascensão da Internet e do jornalismo na rede. Marshal McLuhan (Canavilhas, 2001) “afirmava que os conteúdos de um media são sempre daqueles que foram substituídos", se referindo à apropriação da linguagem radiofônica pela televisão. Mas, McLuhan ignorou que novos media se constroem a partir de novas possibilidades de linguagens e características próprias.

No caso da Internet, resolvidas questões técnicas como velocidade e conexão, ela assume papel de mídia, e é urgente definir qual sua linguagem e características materiais e imateriais, de forma a agregar valor à cibernotícia. Assim, a partir de softwares (como o Flash) e novas ferramentas (como as de georeferenciamento Google Earth) é possível definir a multimidialidade (convergência dos meios) como elemento principal da cibernotícia, bem como a possibilidade de leitura não-linear e única para cada leitor?

A Internet é midia ou apenas uma ferramenta? Abordagens históricas acerca do nascimento dos meios trazem a associação entre estes e a produção de cultura própria do capitalismo e da formação da burguesia e da vida urbana. Pereira (2003) a defende como mídia, considerando que:

(1) a internet deve ser enquadrada dentro de uma nova definição de meio de comunicação que leve em conta o processo comunicativo no atual momento histórico-social; (2) a narratividade, as formas de produção e a lógica da rede, entre outras variáveis representam singularidades do novo meio e não o desqualificam como tal (PEREIRA, 2003: s/n).

Os argumentos contrários dizem respeito ao fato de não ser massiva, não ter um conteúdo homogêneo - ser muitas coisas ao mesmo tempo, e por apresentar um formato e condições de produção distintos dos meios tradicionais - impressos e eletrônicos. Não estaria aí a diferença e a condição para sua definição como tal?

Mas, mesmo sem consenso, o certo é que a partir da construção de linguagens próprias - possíveis graças aos seus ferramentais intrínsecos - hardware e software, a Internet se configura como mídia e, nesse contexto, está inserido o jornalismo online e suas diversas possibilida- 
des. Sabe-se que o jornalismo na rede é hibrido, mistura concepções do impresso e agrega novas possibilidades, como a colaboração (caso do chamado jornalismo de fonte aberta e dos blogs) e a interação, bem como cria caminhos para uma leitura única quando possibilita um trajeto não-linear.

A não-linearidade é uma das características mais importantes do ambiente online de informação, atuando tanto na definição de uma linguagem específica, como determinando a leitura. Saindo do paradigma do texto seqüencial do impresso, a proposta de não-linearidade dos documentos digitalizados em rede significa não somente a ausência de uma hierarquia pré-definida no que diz respeito à leitura, como a disposição das informações num espaço tri-dimensional, que se dá de forma não-linear, ou seja, sem um direcionamento prévio de começos, meios e finais.

De que maneira, entretanto, tal configuração da informação pode influir na leitura e no estabelecimento de uma linguagem própria do meio? Ao falar da cultura impressa e do livro, Roger Chartier nos recorda que os dispositivos próprios do livro (códex) - composto por folhas dobradas, reunidas e encadernadas, em substituição aos rolos - transformaram profundamente os usos dos textos. Com essa nova forma material, reforçada pela invenção da página, localizações garantidas pela paginação e pela indexação, tornou-se possível uma relação inédita entre leitor e livro, que incluía, dentre outras coisas, "escrever enquanto se lê, folhear uma obra, encontrar um dado trecho" (Chartier, 2002, p. 106).

Os meios eletrônicos e digitais, da mesma forma, propõem uma revolução não só do estatuto do texto, e de sua técnica de produção, mas também das práticas de leitura, segundo o mesmo autor. Tais práticas são caracterizadas por três pontos fundamentais, segundo o autor, sendo que o primeiro diz respeito à própria disposição textual:

... a apresentação eletrônica do escrito modifica radicalmente a noção de contexto e, ainda, o próprio processo da construção do sentido. Ela substitui a contigüidade física que aproxima os diferentes textos copiados ou impressos num mesmo livro pela sua distribuição móvel nas arquiteturas lógicas que comandam as bases da dados (...) (CHARTIER, 2002, p. 113).

No contexto dos meios digitais, ainda, há que se levar em conta a questão da interatividade. Os hábitos de leitura começam a modificar-se com o surgimento e desenvolvimento de meios nos quais a interatividade é estabelecida como central. Isso acontece especialmente a partir da década de 80, com a introdução dos computadores pessoais e portáteis, quando, de acordo com Santaella, os espectadores (e leitores) começam a se transformar em usuários. Aqui começa uma mudança fundamental em relação aos meios, porque, como usuário, o leitor/espectador terá maior participação em rela- ção à mensagem e ao próprio meio. Nas palavras da autora, "começou a mudar aí a relação receptiva de sentido único com o televisor para o modo interativo ebidirecional queé exigido pelos computadores" (2003, p. 81).

A função do usuário, assim, é aumentada, no que diz respeito à atividade que ele é capaz de exercer no ato de fruição do conteúdo informativo. Para Santaella, isso fica evidente pelo caráter polissêmico e interativo das novas mídias:

As mídias digitais com suas formas de multimídia interativa estão sendo celebradas por sua capacidade de gerar sentidos voláteis e polissêmicos que envolvem a participação ativa do usuário. As duas bases principais para isso estão na convergência de mídias anteriormente separadas e na relação interativa entre o usuário e o texto híbrido que este ajuda a construir (SANTAELLA, 2003, p. 146).

O leitor assume, desta forma, o papel de usuário, uma vez que relaciona-se com a informação de uma forma participativa. Trata-se de uma mudança na própria relação com a linguagem, no dizer de Kerckhove (2003), afetada pela escrita, num primeiro momento, e depois, pela eletricidade, que vai desembocar nas tecnologias digitais. A tecnologia da escrita modificou os primeiros relacionamentos com a linguagem através da separação entre texto e contexto e do isolamento do leitor, dentre outras coisas, segundo o autor; já a eletricidade trouxe todos os sentidos de volta para a linguagem, mas, ao mesmo tempo, "externa as mentes dos leitores na tela e torna mais uma vez públicos os conteúdos (...) da mente privada da escrita" (Kerckhove, 2003, p. 7).

A relação com a linguagem introduz a preocupação com a cognição, que, para esse autor, está presente no hipertexto, já que este introduz uma ação compartilhada, em que os conteúdos das telas estão disponíveis para muitas pessoas, ao mesmo tempo, sincronicamente, ou além do tempo, diacronicamente (2003, p. 10).

Tal reconfiguração do leitor, que passa a usuário, leva em conta, ainda, e mais especificamente, a renovação de hábitos de leitura.

\section{Os leitores do Ciberjornalismo}

A definição da Internet como mídia e de suas características passa pelo conhecimento dos hábitos de leitura do usuário/leitor de notícias na rede, de forma a estabelecer elos com o conteúdo esperado e a usabilidade proposta. Diversos estudos abordam a problemática do leitor/usuário e estes se referem desde ao comportamento cerebral, atitudes e percursos de navegação, relação de gênero - (há diferença entre os caminhos de leitura feitos por homens e mulheres?)- até sócio-econômicos.

Santaella (2004) classifica os usuários/leitores de internet como sendo três: leigo, novato e experto. O leigo utiliza o raciocínio indutivo, que funciona mais ou menos assim: a partir de um caso isolado e de um resultado 
verificado, chega-se à conclusão generalizada de uma regra. É por indução que um hábito se estabelece. Certas sensações são seguidas pela mesma reação, e uma associação se estabelece. É isso que ocorre quando o internauta internaliza um procedimento de navegação, repetido cada vez mais sob a ação de um hábito. Também se caracteriza pelo baixo conhecimento da rede e dos seus instrumentais. Já o novato, utiliza o raciocínio abdutivo para navegar - ato de levantar uma hipótese explicativa para um fato novo. É um instinto racional. Nesse caso, o novo é apreendido por adivinhação. O raciocínio abdutivo é próprio do novato, que pratica a tentativa/erro. Ele vai clicando meio sem rumo em um campo de possibilidades abertas. Sua experiência é típica de um explorador. Finalmente, o experto é aquele que se utiliza um raciocínio dedutivo. Nesse tipo de raciocínio, parte-se de uma regra geral e de um caso isolado observado e, deduz-se disso uma propriedade deste. O usuário experto, por ter internalizado as regras do jogo da navegação, tem sua mente sob o domínio de hábitos ou associações que fazem com que regras gerais suscitem reações correspondentes.

Já os estudos realizados pelo Instituto Poynter, dos Estados Unidos, dentro da projeto Eyetrack ${ }^{1}$, procuram entender o comportamento cerebral dos navegadores. No relatório de pesquisa de $2007^{2}$ está a afirmativa de que os internautas são leitores mais detalhistas do que os de jornais impressos: eles leram $77 \%$ do texto das notícias publicadas online enquanto os leitores de jornais tamanho standard pararam nos $62 \%$, e os dos tablóides não passaram de magros $57 \%$. A maior intensidade de leitura de textos jornalísticos na Web contraria a idéia de que os internautas são superficiais, inquietos e que pulam de uma notícia para outra constantemente. Descobre-se agora que esta percepção não é verdadeira, e que a persistência na leitura pode ser o resultado da crescente preocupação dos jornalistas online em incorporar elementos multimídia na produção noticiosa.

As conclusões surpreenderam, porque até agora se acreditava que a leitura na Web era superficial porque se trata de uma atividade $25 \%$ mais cansativa do que a leitura em papel.

Canavilhas (2001) relata pesquisa desenvolvida em Portugal para estabelecer quais os percursos de leitura estabelecidos pelos usuários/leitores daquele país. De acordo com o autor, foi preparada uma notícia com 10 páginas de web ligadas através de links em menu e embutidos nos textos. Aos pesquisados, alunos da Universidade da Beira, 39 no total, foi explicado que deveriam ler como sempre o faziam. Os resultados mostraram até 55 possibilidades de leitura. E mais:

a) $76,5 \%$ dos utilizadores passou ao segundo nível seguindo o primeiro link embutido no texto. Deste grupo, $57,7 \%$ passou para o terceiro nível da notícia, seguindo o único link embutido neste segundo texto.
No outro texto de segundo nível com enlace embutido, $67,6 \%$ dos utilizadores seguiu esse link para o terceiro nível.

b) $23 \%$ dos leitores tem uma rotina de leitura por nível: se- guem o link no local onde está inserido, regressando de seguida ao texto inicial.

c) $77 \%$ segue o seu próprio percurso de leitura: no primeiro momento em que os leitores foram confrontados com vários links;

(5) identiûcaram-se 5 percursos diferentes; no segundo passo a variedade de percursos subiu para 11 e no terceiro já existiam 22 percursos de leitura diferentes, em 55 possíveis; d) 11,1\% dos leitores seguiram um percurso de leitura idêntico, fazendo 11 passos iguais ( CANAVILHAS, 2001, p. 9-10).

Finalmente, na Espanha, a Associação para Investigação dos Meios de Comunicação ${ }^{3}$ - também buscou respostas para os padrões de leitura e navegação no cirbejornalismo. Descobriu que são dois: um masculino e outro feminino, parecidos, mas não iguais. Enquanto os homens lêem em forma de ziguezague, as mulheres lêem de forma vertical. Em ambos os casos o que chama a atenção dos leitores são os conteúdos gráficos, distraindo a leitura.

Esses resultados mostram a diferença intrínseca entre o texto jornalístico impresso e o eletrônico: no impresso a preocupação é a dimensão do texto e os recursos de estilo para traduzir a informação em determinado espaço; já no segundo caso, a preocupação é por conta da organização das informações, ou da arquitetura da informação.

\section{Pirâmide ou não - eis a questão}

Para além das discussões acerca da Internet como mídia e dos hábitos de leitura de seus usuários, no caso do jornalismo uma discussão central é em como se dará o ordenamento das informações, mediante a diversidade de padrões de leitura.

Alguns pesquisadores como JaKob Nielsen (1996), Rosental Alves (2004) ou José Álvarez Marcos (2003), Maria Jose Cantalapiedra (in: CASTILHOS, 2005) e outros, insistem na importância da pirâmide invertida nos meios online. Cantalapiedra defende a técnica exclusivamente para a cibernotícia. Para ela, o jornalista deve "ter capacidade para contar num parágrafo o que se passa". Ou seja, do mais importante para o menos importante buscando no lead as respostas para "O quê?, quem?, quando?, onde?, como?, e por quê?". Segundo Adelmo Genro Filho, em "O Segredo da Pirâmide", o lead deve descrever a maior singularidade da notícia. Deve informar qual é o fato jornalístico noticiado e as principais circunstâncias em que ele ocorre.

Outros como Knobloch \& all (2004) e Canavilhas (2001) são contrários ao uso da técnica e baseiam suas afirmações na possibilidade da não-linearidade. Canavilhas propõe, inclusive, o que chama de pirâmide deita- 
da, onde o ordenamento das informações se dá por blocos: (1) unidade de base, onde é respondido o essencial; (2) nível de explicação, que contém o por quê e o como, complementando o essencial; (3) nível de contextualização, onde podem ser oferecidas outras informações com fotos, infográficos, textos e mesmo vídeos e (4) nível de exploração - que pode ligar a notícia a arquivos externos, como um banco de dados ou da própria rede.

Além de reconhecer tal diversidade da leitura, determinada pela navegação, e a estrutura da notícia, pensar a informação no jornalismo online implica também verificar as características específicas de sua linguagem. Pergunta-se, então, o que, de fato, terá influência sobre a construção da notícia na internet? Questões como a nãolinearidade, a interatividade e a convergência de meios têm, efetivamente, um papel na estruturação da informação online?

\section{Convergência de meios e linguagens}

A internet é um meio que está se desenvolvendo a partir de remodelação de meios anteriores, para usar as palavras de Bolter e Grusin (1999). Ainda que esses autores não estejam falando especificamente de linguagens, está implícito que em tal remodelação, a linguagem acaba também sofrendo manipulações, combinações e rearranjos, resultando na hipermídia. A plataforma da Web, assim, é suporte para esta nova linguagem, e o jornalismo online tem utilizado esses fatores em prol de uma eficácia cada vez maior do ato informativo. Desta forma, o jornal, o livro, a televisão, o rádio e o design gráfico, por exemplo, enquanto meios e suas linguagens, são remodelados no ambiente digital.

A eletricidade, desde o tempo do telégrafo, segundo Kerckhove (2003), formatou a linguagem, transformando-a em ubíqua, instantânea e, agora, em digital.

Através da tradução de toda experiência, incluindo as sensoriais, em uma mesma substância simplificada, a digitalização permite que as experiências retornem às tecnologias da troca lingüística. É isto que significa multi ou hipermídia (visão, audição), realidade virtual (sinestesia), sistemas interativos (tato) (Kerckhove, 2003, p. 8).

A utilização das possibilidades do meio digital tem sido ressaltada pelos chamados "especiais multimídia" segundo Longhi $(2008$, p. 4), também definidos como pacotes de Flash, nas palavras de Mindy McAdams (2005, p. 3), que atenta para o fato de que estes produtos informativos são produzidos utilizando-se a tecnologia do software Flash, "capaz de incorporar áudio, vídeo, animação, fotos e texto, harmonizando-os dentro de uma interface simples e consistente" (McAdams, 2005, p. 11).

A característica principal destes pacotes, que podemos remeter às grandes reportagens do impresso e mesmo da televisão, remodelados agora na Web, é que se constituem em formatos específicos do jornalismo onli- ne, aproveitando as possibilidades de convergência de linguagens própria do meio digital possibilitadas pela hipermídia (Longhi, 2008, p. 2). Neste sentido, os pacotes em Flash parecem sinalizar para o que de mais avançado está acontecendo no jornalismo, mostrando que a combinação de meios e linguagens talvez seja o fator principal da especificidade da informação no formato digital, ressaltada, ainda, pela fusão conceitual de meios, que definimos como intermídia (Longhi, 2008). Intermídia seria um modo de olhar para tal combinação de linguagens, que vai além da simples colocação dos formatos na tela: traduz-se mais pela combinação conceitual, pela mistura de meios que, ao se mesclarem, operam no nível mais profundo da expressão, mantendo algumas características e adquirindo outras, sempre remodelados pelo suporte.

A noção de intermídia fica mais evidente com o avanço no desenvolvimento e utilização de ferramentas como o Flash, que permitem, efetivamente, que se verifique a fusão conceitual. Isso mostra, também, que o leitor dos meios digitais foi evoluindo, ou seja, suas práticas de leitura aperfeiçoaram-se, acompanhando o desenvolvimento das ferramentas, aliadas à velocidade de transmissão de dados, dentre outros fatores.

Desta forma, pode-se afirmar que o leitor define, através de sua função, os formatos da notícia, uma vez que sua ação sobre o meio será levada em consideração no momento de pensar a estrutura da informação nos meios digitais $\square$ FAmECOS

\section{NOTAS}

1 O projeto Eyetrack usa um sofisticado equipamento eletrônico que acompanha o movimento do globo ocular de uma pessoa enquanto ela lê um texto. Esta é a primeira vez que o mesmo sistema é usado em jornais impressos, o que permitiu a comparação.

2 Seiscentas pessoas, que leram um total de $9.000 \mathrm{mi}-$ nutos em sessões de 15 minutos, participaram dos testes que serviram de base para o relatório 2006/ 2007, o mais amplo de todos os quatro informes publicados até agora neste projeto cujo objetivo é verificar se a maioria das regras sobre organização e leitura de textos tem ou não base na realidade. Consulte o site: http:/ / www.nngroup.com/. Acesso em 29 de maio de 2008

3 http://www.alt64.com/ eyetrackingmedia/ patron_de_navegacion.php. Acesso em 21 mai de 2008

\section{REFERÊNCIAS}

ÁLVAREZ MARCOS, J. El periodismo ante la tecnología hipertextual. In NOCI, J. D.; SALAVERRÍA, R., coord. - Manualde redacción ciberperiodística. Barcelona: Ariel Comunicación, 2003. 
BOCZKOWSKI, Pablo J. Digitalizar las noticias. Innovación em los diários online. Buenos Aires: Manantial, 2006.

BOLTER, J. David e GRUSIN, Richard. Remediation. Understanding New Media. Cambridge, Mass.: The MIT Press, 1999.

CANAVILHAS, João. Webjornalismo: Da pirâmide invertida à pirâmide deitada.

Disponível em http:/ / www.bocc.ubi.pt/pag/canavilhas-joao-webjornalismo-piramide-invertida.pdf. 2001. Acesso em 23 de maio de 2008.

CASTILHO, C. - Uma linguagem em construção. In: $O b$ servatório da Imprensa. http:// observatorio.ultimosegundo.ig.com.br / artigos.asp?cod=3 11ENO002, 2005. Acesso em 25 de abril de 2008.

CHARTIER, Roger. Os desafios da escrita. (Trad.: Fúlvia M. L. Moretto). São Paulo: Ed. da UNESP, 2002.

KERCKHOVE, Derrick de. Texto, contexto e hipertexto: três condições da linguagem, três condições da mente. In: Revista Famecos, Porto Alegre: 2003, pp. 7-12.

KNOBLOCH, S. et al. Affective News : effects of discourse structure in narratives on suspense, curiosity, and enjoyment while reading news and novels In:. Communication Research. 31:3, (June) 259-287, 2004.

LONGHI, Raquel. Infografia online: narrativa intermídia. Artigo apresentado no GT Estudos de Jornalismo, $17^{\circ}$ Compós, São Paulo, 2008.

MCADAMS, Mindy. Flash journalism. How to create multimedia news packages. Burlington, MA, USA: FocalPress/Elsevier, 2005.

MURRAY, Janet. Hamlet on the Holodek. The future of narrative in cyberspace. Cambridge, Mass.: MIT Press, 1997.

NIELSEN, Jakob .Inverted Pyramids in Cyberspace. Em http://www.useit.com/alertbox/9606.html, 1996. Acesso em 17 de abril de 2008

NOCI, Javier Díaz. SALAVERRIA, Ramón. Manual de redacción ciberperiodística. Barcelona: Ariel Comunicación, 2003.

PATERSON, Crhis. DOMINGO, David, Making online news: the ethnography of new media production. NEW YORK: Peter Lang Publishing Inc, 2008.

PEREIRA, Fábio. MORAES, Francilaine. Mas, afinal, a
Internet é mídia?. Artigo apresentado do XXVI Congresso das Ciências da Comunicação. Belo Horizonte, 2003. Disponível em http://www.portalrp.com.br/bibliotecavirtual/comunicacaovirtual/ 0221.pdf. Acesso em 23 de abril de 2008.

SALAVERRIA, Ramón . De la pirámide invertida al hipertexto. Disponível em http://www.unav.es/fcom/ mmlab/mmlab/investig/piram. 2001.

Acesso em 18 de mai de 2008

SANTAELLA, Lúcia. Culturas e Artes do Pós-humano. Da cultura das mídias à cibercultura. São Paulo: Paulus, 2003.

Navegar no ciberespaço. Perfil cognitivo do leitor imersivo. São Paulo: Paulus, 2004.

ZAMITH, Fernando. Pirâmide invertida na cibernotícia: a resistência de uma técnica centenária. Disponível em www.comunicacao.org.br/jk/component/ option,com_docman/task,doc_download/gid,732/ Itemid,186. Acesso em 16 de maio de 2008. 